\title{
A leitura das narrativas sagradas: uma crítica à exegese tradicional à luz da Semiótica da Cultura e Teorias Narrativas
}

\author{
The reading of sacred narratives: a critique of traditional exegesis from the \\ Semiotics of Culture and Theory Narratives
}

Kenner Roger Cazotto Terra*

\begin{abstract}
Resumo
A interdisciplinaridade, tema caro para as pesquisas científicas, gerou profundas e renovadoras mudanças nas perguntas feitas aos textos, que giravam sempre em torno da autoria, fundo histórico e genealogia de tradições. Observando a história do estabelecimento das ciências da religião, desde os primeiros trabalhos de Max Müller, sabe-se que a leitura das narrativas sagradas foi fundamental. Estas são expressões de linguagem oral ou escrita do ambiente religioso. Neste texto, serão apresentadas as intuições da semiótica da cultura de I. Lótman e colocadas em diálogo com as teorias narrativas, para serem pensados pressupostos epistemológicos e metodologias, menos devedores das metodologias historicistas, a fim de servirem de instrumento para interpretação destes textos sacralizados pelas comunidades religiosas. Para este feito, serão apresentados e discutidos conceitos como texto, cultura, memória e narrativa, os quais permitirão fazer as devidas críticas às metodologias tradicionais que se cristalizaram na prática interpretativa, especialmente na exegese filha da Modernidade, como, também, propor novas perguntas e caminhos na compressão dos textos das religiões.
\end{abstract}

Palavras-chave: narrativas sagradas, texto, cultura, semiótica da cultura.

\begin{abstract}
Interdisciplinary generated deep and renewing changes in questions to the texts, which always revolved around authorship, historical background and genealogy of traditions. Observing the history of the establishment of sciences of religion from the early works of Max Müller, it is known that the reading of sacred narratives was fundamental. These are expressions of oral or written language of the religious environment. In this text, the intuitions of semiotics of culture of I. Lotman will be presented and put into dialogue with the narrative theories, to be thought some epistemological and methodological assumptions, less debt of historicist methodologies in order to serve as a tool for interpreting these sacralized texts by religious communities. For this done, will present and discuss concepts such as text, culture, memory and narrative, which will allow to make the necessary criticisms of the traditional methodologies crystallized in interpretative practice, especially in the child exegesis of modernity, as also propose new questions and ways in compression of the religious texts.
\end{abstract}

Keywords: sacred narratives, text, culture, semiotics of culture.

Artigo recebido em 15 de janeiro de 2016 e aprovado em 29 de agosto de 2016.

* Mestre e doutor em Ciências da Religião, pela Universidade Metodista de São Paulo (UMESP), membro do Grupo Oracula de Pesquisa, membro da SBL (Society of Biblical Literature), professor na graduação em teologia e no programa de mestrado profissional na Faculdade Unida de Vitória (FUV). País de origem: Brasil. E-mail: krcroger@gmail.com.

Horizonte, Belo Horizonte, v. 14, n. 43, p. 859-889, jul./set. 2016 - ISSN 2175-5841 


\section{Introdução}

Nos últimos anos, a teoria da memória tem passado por reavaliações. Os trabalhos de Maurice Halbwachs, por exemplo, abriram as portas para o mundo coletivo das memórias, por vezes tratadas como expressões individuais (HALBWACHS, 2006; RICOEUR, 2003; BLOCH, 1998). Como parte desta discussão, serão apresentadas as intuições da semiótica da cultura de I. Lótman, as quais vinculam "memória" e "cultura" para o projeto de construção conceitual. Dentro da mesma tarefa de formação de referencial teórico, colocaremos em diálogo as teorias narrativas, que revelam pressupostos epistemológicos e metodologias menos devedores aos instrumentos historicistas.

A semiótica da cultura permitirá observarmos com cuidado os conceitos memória, texto e cultura e suas implicações para as ciências do texto, os quais ajudarão na leitura dos textos sagrados. Desta maneira, perceberemos como essas discussões possibilitam o diálogo com os pressupostos epistemológicos da Narratologia, que pensa a narração como mecanismo estratégico do narrador sobre o narratário e não a reprodução da realidade ou do passado. O artigo fará (1) a descrição e análise crítica dos conceitos de texto, cultura e memória da semiótica da cultura de I. Lótman e da Escola de Tártu-Moscou; (2) a apresentação do conceito de narrativa a partir dos trabalhos da Narratologia; (3) nesse ponto propor-se-á uma crítica à exegese tradicional e, consequentemente, às leituras historicistas.

\section{Semiosfera: Semiótica da cultura e a leitura de textos sagrados}

As pesquisas de I. Lótman a respeito da memória orientam-nos para novos caminhos em relação ao trato dos textos sagrados. Para o semioticista soviético, a cultura, antes de qualquer coisa, é uma inteligência coletiva ou memória coletiva supraindividual. Segundo Lótman, a cultura é um mecanismo de conservação e transmissão de certos comunicados (textos) e elaboração de novos textos 
(LÓTMAN, 1996, pp.77-82). Os conceitos de "cultura" e "texto" desse autor precisam ser bem explicados, pois são exatamente essas as duas expressões axiais para a sua argumentação sobre a relação da cultura com a memória.

Cultura é, então, "fenômeno interativo sem existência isolada e com um campo conceitual unificado fundado no processamento, na troca e na armazenagem de informações" (MACHADO, 2003, p.28). Assim sendo, a cultura é interativa e traz para o centro de si outros mundos (MACHADO, 2003, p.110). E como a cultura é uma organização de significantes e significados, ela por si já é um texto. Pode-se afirmar que a cultura é definida em traços mínimos como texto porque há nela estruturalidade.

Neste sentido, os sistemas culturais são textos não porque se reduzem à língua, mas porque sua estruturalidade procede da modelização a partir da língua natural. Os sistemas modelizantes de segundo grau se organizam ou se arranjam a partir de sistemas modelizantes de primeiro grau. Ou seja, a cultura opera como organizadora de sinais, os quais, estruturados, tornam-se comunicação. Como explica Paulo Nogueira, esses são os sistemas da cultura que dão forma ao que é amorfo, da mesma forma que a língua natural organiza em mundo humano a natureza (NOGUEIRA, 2012b). No limite desse raciocínio situa-se a síntese sistêmica: o conceito de cultura como texto, na verdade, deve ser entendido como texto no texto. Todo texto da cultura é codificado, no mínimo, por dois sistemas diferentes. Por conseguinte, todo texto da cultura é um sistema modelizante (MACHADO, 2003, p.39).

Por isso, Irene Machado pode dizer que "a cultura como texto implica a existência de uma memória coletiva que não apenas armazena informações, como também funciona como um programa gerador de novos textos, garantindo assim a continuidade" (MACHADO, 2003, p.102). A cultura é a anexação de textos e os textos são unidades básicas da cultura. Para isso ser possível, pensa-se a cultura na lógica da negação radical da existência de qualquer signo isoladamente. Um signo 
requer outro signo; um texto requer outro texto. O texto não é fenômeno isolado, mas pertence a um grande sistema, chamado por Lótman de semiosfera, o resultado e a condição para o desenvolvimento da cultura, fora da qual não pode haver linguagem e comunicação (LÓTMAN, 1990). A semiosfera pode ser definida, antes de qualquer coisa, a partir deste princípio: as coisas não existem isoladamente. Dessa forma, podemos definir a semiosfera por alguns pontos (VIEIRA, 2007, p.99-103):

1.Semiosfera é um conjunto de textualidades, um texto junto de outro texto que faz dele um texto; sem textos prévios não há texto; 2.Semiosfera é algo formado por uma rede (interminável) de interpretações; ou 3. Semiosfera é a esfera da comunicação; 4. Semiosfera é uma rede processual de signos ou semiose; 5 . Semiosfera é o lugar de todos os Umwelts (ambientes/meio ambiente) interconectados. Dois Umwelts quaisquer, quando em comunicação, são parte de uma mesma semiosfera; 6.Semiosfera é o espaço das semioses; 7.Semiosfera é o lugar de organização de sentido; 8. Semiosfera é o espaço da relação parte-todo.

O semioticista define semiosfera, por analogia ao conceito de biosfera, como o funcionamento dos sistemas de significações de vários tipos e níveis de organização. A biosfera é sua analogia preferida por ser um conceito que serve, obviamente, para pensar o continuum semiótico (LÓTMAN, 1996, p.21), o qual nos mostra a unidade, inter-relação e conservação do cosmo.

Podemos continuar descrevendo a semiosfera, pois é o turning point dos conceitos da semiótica da cultura e como a textualidade se realiza em seu ambiente. Na bioesfera a matéria é vista como unidade orgânica, formada por organismos vivos, os quais não podem viver e existir isoladamente; um precisa do outro. Homens, mulheres ou quaisquer organismos vivos são uma função da biosfera em um determinado espaço-tempo (LÓTMAN, 1996, p.23).

Também em relação à semiótica é possível um enfoque análogo. Pode-se considerar o universo semiótico como um conjunto de distintos textos e linguagens fechadas em relação umas com as outras. Então, todo o edifício tem a aparência de 
estar construído de distintos tijolos. Sem dúvida, parece mais frutífera a abordagem de outra forma: todo o espaço semiótico pode ser considerado como um mecanismo único (mas como um organismo). Então, ele não é um ou outro tijolo, mas o "grande sistema", denominado semiosfera. A semiosfera é o espaço semiótico fora do qual é impossível a existência da semiose [...] (LÓTMAN, 1996, p.24).

A semiosfera é delimitada. Assim, há os espaços extrasemiótico e alosemiótico que vivem na fronteira da semiosfera. Estes são determinados pelo olhar do outro. A partir do ponto de vista interno de uma cultura pode-se olhar para um externo não semiótico; ou seja, os limites de determinada cultura dependem do observador (LÓTMAN, 2005, p. 213).

Aqui chegamos a outro conceito importante para o estudo desse conceito para a semiótica da cultura, "fronteira": "a fronteira semiótica é a soma dos filtros tradutores - filtros bilíngues através dos quais passam um texto que é traduzido à outra linguagem (ou linguagens) que está fora de dada semiosfera" (LÓTMAN, 1996, p.24). A fronteira é o mecanismo que traduz as mensagens externas para a linguagem interna da semiosfera. Os textos não semióticos ou alosemióticos estão fora desse espaço e a fronteira delimita o âmbito individual da semiosfera. Contudo, esse espaço é um conjunto de linguagens que se organizam de modo coletivo, criando unificação identitária coletiva. Com a fronteira se cria uma pessoa coletiva pela qual há o relacionamento com os demais textos dos espaços não semióticos; sem a fronteira não há contato com os espaços outros.

A função da fronteira, como uma espécie de superfície orgânica da biosfera, reduz-se a limitar a penetração do texto inteiro, filtrando-o e elaborando-o adaptativamente. Em diversos níveis, essa função invariante se realiza de diferentes modos (LÓTMAN, 1996, p.26). No nível ou em relação à semiosfera, (1) tem o objetivo de determinar o que é próprio, diferenciando-o do outro; (2) serve de filtro para as mensagens externas, (3) traduzindo-a para a sua própria, como 
também (4) convertendo as não mensagens externas em mensagem, o que seria a sua transformação semiótica em informação. Isso significa a separação do próprio em relação ao alheio. É a fronteira que traduz para dentro do espaço da semiose o externo, o desconhecido, não controlado, tornando-o, ao modelizá-lo, algo comum, mas transformado, gerando também transformações na linguagem interna.

Em primeiro lugar é pela fronteira que se torna possível apreender as trocas operacionais sígnicas [...]. O processo relacional instaurado entre dois ou mais sistemas modelizantes não corresponde a uma transferência linear de informações. Vale lembrar que a tradução aqui referida é um processo modelizante e, enquanto tal, recodifica o sistema ao modelizá-lo em outra configuração. Esta forma de correlação entre sistemas impossibilita o estabelecimento de uma conexão simples e direta entre distintas esferas, pois neste processo opera-se a tradução entre códigos com características singulares, resultando na redefinição dos mesmos, de modo que um mesmo código nunca "chega" a um sistema tradutor, uma vez que a "intromissão" de um novo código pode ocasionar a redefinição da linguagem característica de uma unidade sígnica (RAMOS, et. al., 2007, p.38).

Também, ao definir os espaços semióticos e não semióticos, cria-se a ideia de individualização e relação com os outros sistemas. No entanto, esse não é um espaço fechado, mas aberto a transferências informacionais.

Outra expressão importante para a semiótica da cultura é o conceito de texto. Para Lótman e sua escola, o texto é um espaço semiótico de troca e diálogo no qual as línguas vivem a lógica da interação e interorganização em processos de modelização. A grande contribuição dessa iniciativa para a pesquisa centra-se na compreensão da religião como um sistema de comunicação e elaboração de mensagens: "texto da religião" ou "texto cultural da religião" (NOGUEIRA, 2012a p.16-17).

O texto, para Lótman, tem três funções: (1) função comunicativa; (2) função geradora de sentido; (3) função mnemônica (LÓTMAN, 2007). A primeira função foi a mais observada pelos linguistas durante muito tempo. Esta mostra o texto como processo de realização da língua natural. A função da linguagem seria transmitir a mensagem de um emissor ao receptor - qualquer ruído atrapalharia a 
função do texto. Essa função se refere aos textos monossêmicos, manualísticos. A segunda função tem relação com o seu potencial polissêmico, o que proporciona a produção de novos textos no ato da comunicação de textos não mecânicos/manuais.

Os códigos que decifram os textos deformam o texto do emissor. No encontro dos códigos, para decifrá-los, acontece o ruído que seria o potencializador da renovação. O código do emissor A é diferente daquele do emissor B e, no contato do código A com o B, gera-se um novo texto: quem lê o texto tem pressupostos, questões e conhecimentos diferentes do emissor (NOGUEIRA, 2012b, p.22). O ruído, na verdade, é o necessário corolário do encontro dos códigos de quem produz e quem lê o texto. Dessa maneira, o ruído, enquanto resultado das complexas relações inerentes ao poliglotismo interno do texto, torna-se o responsável pela gestação de novos sentidos (RAMOS, et.al., 2007, p.32).

A terceira função do texto é a mnemônica. Como bem diz Lótman, "o texto não é somente o gerador de novos significados, mas também um condensador de memória cultural. Um texto tem a capacidade de preservar a memória de seus contextos prévios" (LÓTMAN, 2007, p.22). Esse processamento se faz possível por meio da tradução de tradições (LÓTMAN, 1993, p.19). Dinâmica, a cultura pode codificar e decodificar mensagens de períodos diversos, traduzindo-as em novos sistemas de signos e de textos, agindo como uma engrenagem complexa de seleção das informações mais necessárias (FERRARI, 2007, p.256). Por isso, as culturas, enquanto textos, sempre se enriquecem recíproca e constantemente, pois é circular. Como descreve Paulo Nogueira:

Este é um conceito central da semiótica da cultura, pois neste caso o texto adquire uma personalidade semiótica. Ele evoca os demais textos por meio dos quais foi interpretado. Ele também traz em si as memórias de sua leitura e dos eventos históricos que ocorreram fora de si, mas que nele podem evocar associação. Ou seja, o texto não é uma mensagem inerte, estática, mas antes uma mensagem que se auto-organiza e que se relaciona com outros textos. Este processo de preservação de memória é um sistema poderoso para criação de novos textos (NOGUEIRA, 2012b, p.18). 
A cultura se apresenta como um mecanismo dinâmico que traduz mensagens em novos textos ou sistemas de signos. Por isso,

cultura é memória, ela relaciona-se necessariamente com a experiência histórica passada. [...]. A própria existência da cultura pressupõe a construção de um sistema de regras para a tradução da experiência imediata em texto" (LÓTMAN, USPENSKII, 1981, p. 37).

Os textos da cultura refletem esses encontros e trocas, os quais se processam a partir da tradução de tradições, que é feita criativamente, dando aos signos anteriores novos contornos que, por si, são cheios de possibilidades. A semiótica da cultura seria, nessa perspectiva, "a disciplina que examina a interação de sistemas semióticos diversamente estruturados, a não uniformidade interna do espaço semiótico, a necessidade do poliglotismo cultural e semiótico" (LÓTMANN, 1996, p.78). Por essa e outras razões, os textos sempre serão criativos e estratégicos na apropriação das memórias que os antecedem:

o texto cumpre a função de memória cultural coletiva. Como tal, mostra, por um lado, a capacidade de enriquecer-se ininterruptamente e, por outro, a capacidade de atualizar alguns aspectos da informação depositada nele e esquecer outros temporalmente ou por completo (LÓTMAN,1993, p.19).

Aqui percebemos a função própria da cultura, que é ser ambiente de trânsito das memórias e sua própria possibilidade de existência. As memórias são elementos principais da cultura, esta que processa informações, organizando-as em algum sistema de signos ou de códigos naturais.

Minha afirmação, contudo, não deve ser entendida como um postulado teórico. Na verdade, parto do princípio de que a cultura dispõe de mecanismos semióticos que lhe são inerentes. Um deles é o processamento de toda e qualquer informação em texto graças ao dispositivo da memória. Antes de entrar no mérito da discussão da cultura como texto é preciso estabelecer as bases da cultura como informação, onde o elemento-chave é a memória - a memória não-hereditária (sic) que garante o mecanismo de transmissão e conservação. A cultura, todavia, compreende não só uma determinada combinação de sistemas de signos como também o conjunto das mensagens que são realizadas historicamente numa língua (ou texto). Traduzir um setor da realidade em 
uma das línguas da cultura, transformá-la numa codificação, isto é, num texto, é o que introduz a informação na memória coletiva. Neste sentido, a afirmação segunda a qual a vida nada mais é do que uma luta pela informação deve ser ampliada e completada: a história intelectual da humanidade pode ser considerada uma luta pela memória (LÓTMAN Apud MACHADO, 2003, p.38).

É no espaço da cultura que textos podem ser preservados e atualizados. Por isso Lótman fala sobre a "memória comum", que é formada por alguns textos constantemente presentes. No entanto, essa unidade se dá apenas em certo nível por causa dos dialetos da memória, que são organizações internas dentro da memória comum de uma coletividade cultural; estas estão dentro do mundo da cultura dada. Do ponto de vista da semiótica, e aqui está a relação entre cultura e memória, cultura é um espaço no qual se opera a movimentação das memórias na prática da conservação e transmissão:

Desde o ponto de vista da semiótica, a cultura é uma inteligência coletiva ou uma memória coletiva; isto é, um mecanismo supraindividual de conservação e transmissão de certos comunicados (textos) e de elaboração de outros novos. Nesse sentido, o espaço da cultura pode ser definido como um espaço de certa memória comum, isto é, um espaço limitado dentro do qual alguns textos comuns podem conservar-se e serem atualizados [...]. Assim, pois, a memória comum, para o espaço de uma cultura dada, é assegurada, em primeiro lugar, pela presença de alguns textos constantes e, em segundo lugar, ou pela unidade dos códigos, ou por sua invariação, ou pelo caráter ininterrupto e regular de sua transformação (LÓTMAN, 1996, p.157).

Podemos destacar duas questões dessa afirmação: (1) a cultura como memória coletiva, supra-individual, de conservação e transmissão de textos - isso implica a aceitação da presença na semiosfera de textos que precedem as relações e significações sincrônicas; (2) a perenidade assegurada por unidades de códigos e transformações. Lótman diz que a memória da cultura não é somente uma, mas é internamente variada, o que permite a presença de subestruturas culturais com diferentes composições e volumes de memórias, surgindo semânticas locais. No entanto, textos eliptizados, que estão no nível de uma subcoletividade, quando passam de seus limites locais precisam ser completados com glossários, comentários, etc. para serem compreendidos. Isso testemunha a passagem dessa 
esfera para uma coletividade com outro volume de memórias (LÓTMAN, 1996, p.160).

Como tenho dito, para Lótman, a memória é a conservação de textos. Interessante é a afirmação lotmaniana de que os textos atuais sempre serão iluminados pela memória, e os não atuais passam a existir como potencialidade. Assim, os textos atuais são iluminados pela memória, mas os não atuais não desaparecem, passando a existir em potêncialidade.

Por isso Lótman pode falar que a memória cultural é pancrônica (sincrônica e diacrônica), bem como se opõe ao tempo - conserva o passado como algo que está (LÓTMAN, 1996, p.162). No entanto, não perde de vista que essa presença não é o passado enquanto realidade passiva, mas se insere na dinâmica da memória que gera novos textos.

Para Lótman, como se tem dito, o que forma a "memória comum" são textos preservados como uma espécie de cânon da cultura, de dentro do qual surgem subculturas com suas memórias e coletividades locais. Contudo, uma pergunta logo nos vem: qual é o processo que gera certas conservações e esquecimentos? Cada cultura define seu paradigma do que se deve recordar (isto é, conservar) e o que se deve esquecer. Este último é apagado da memória da coletividade; é "como se deixasse de existir". Mas com as mudanças temporais, o sistema de códigos culturais muda o paradigma gerador de memória-esquecida. O que se declara verdadeiramente existente pode tornar-se "como se não existisse", e o que deve ser esquecido e o que não existiu pode ganhar peso de existente e significativo (LÓTMAN, 1996, p.160).

A cultura, em um processo não previsto e fruto de sua dinâmica, segundo Lótman, passa por mudanças de sistemas de códigos e isso pode servir para trazer à existência o que foi decretado memória esquecida, assim como apagar/esquecer as memórias vivas. Contudo, não somente muda-se o conjunto dos textos, como também os próprios textos, pois sob a influência de novos códigos utilizados para 
decifrar os textos acontecem deslocamentos dos elementos significativos e não significativos da sua estrutura. Por isso. os sentidos da memória cultural "não se conservam, mas crescem" (LÓTMAN, 1996, p.160). Eis aí a dinâmica na memória cultural de esquecimento e lembrança.

Seguindo elucubrações lotmanianas, os textos que formam a "memória comum" de uma coletividade cultural servem para interpretar os que circulam em corte sincrônico da contemporaneidade da cultura, bem como geram novos textos. A memória cultural, formada por textos perenizados, serve como uma espécie de óculos para interpretação dos textos que compõem a semiosfera, além de agirem na criatividade e criação de novos comunicados (textos).

Quando os textos da memória cultural entram em choque com os textos contemporâneos, a produtividade de sentido depende do espaço da lacuna semiótica, o que gera uma explosão na gramática cultural, que é resultado do encontro rico dos textos da cultura com os da contemporaneidade.

Pensando o conceito de memória cultural, os textos bíblicos ou as narrativas sagradas em geral, seriam suporte também para memória cultural. Ou seja, no caso dos textos bíblicos, poderiam formar a memória comum para interpretação e geração de novos textos na semiosfera greco-romana e judaica. De outra maneira, se até mesmo as expressões mais individuais estão em diálogo com tradições, que são mecanismos vivos de comunicação, podemos perceber que os textos judaicocristãos fornecem exemplos da dinâmica da formação e organização dos arquivos e cânon da memória cultural.

Se a memória cultural revela-se como conjunto de elementos da cultura (como palimpsesto, organiza-se dinamicamente), seria, então, possível determinar em quais e com quais memórias o texto cria identidades, constrói realidades ou interpreta mundos. Seja a memória comunicativa ou cultural, sempre haverá conjuntos de imagens, discursos, etc. que coexistem. Nesse sentido, o texto sagrado, quando preserva ou está em diálogo contratual com algumas memórias, 
pode nos dar pistas a respeito da identidade na qual se insere, mesmo que retoricamente.

Assim sendo, cabe-nos aqui passarmos para a apresentação do conceito de narrativa e as contribuições da Narratologia, pois esta pode servir instrumentos e pressupostos que completam e dialogam com a Semiótica da Cultura. Nesse ponto, como estão em jogo as discussões metodológicas e os aportes teóricos para o trabalho com os textos, faz-se necessária uma crítica ao método histórico-crítico, especialmente sua dívida para com a intenção autoral, seu conceito de texto e sua ideia de acesso à realidade para se perceber como a Narratologia dialoga melhor com as intuições dos referenciais acima.

\section{Construção da realidade versus acuracidade da linguagem}

Esta parte do trabalho apresentará subsídios teóricos que foram desenvolvidos para os estudos das narrativas, espacialmente a partir 1970. As pesquisas realizadas por Robert Alter (ALTER \& KERMODE, 1997; ALTER, 2007), por exemplo, mostram a aplicação das teorias narrativas aos textos bíblicos. Como exemplos frutíferos desta perspectiva aos textos bíblicos, podemos citar os trabalhos realizados pelo Narrative Research Group da Society of Biblical Literature (década de 1980), os quais resultaram na publicação do número 46 da revista Semeia (AMIHAI; COATS; SOLOMON, 1989, p. 1-178)ํ. Nestes artigos, as teorias narrativas são aplicadas aos textos da Bíblia Hebraica.

Assim, precisamos pensar os avanços realizados pelas teorias literárias adotadas para a Bíblia ou textos sagrados em geral. Essas pesquisas apresentam novas questões aos textos e acabam se tornando uma indireta crítica à exegese tradicional, que tem suas bases em conceitos tais como intenção autoral, contexto histórico e leitores reais.

\footnotetext{
${ }^{1}$ Para uma exposição das pesquisas a respeito da aplicação das teorias narrativas à Bíblia, em especial à Bíblia Hebraica, cf. GUNN, 1979, p, 65-75.
}

Horizonte, Belo Horizonte, v. 14, n. 43, p. 859-889, jul./set. 2016 - ISSN 2175-5841 
$\mathrm{Na}$ história da interpretação - que pode ser confundida com a própria história do desenvolvimento das ciências humanas - o "autor", "texto" e "leitor" se tornaram mundos em favor dos quais as perspectivas hermenêuticas lutaram pela defesa do seu valor e imprescindibilidade na “compreensão”, “construção” ou "criação" do sentido. Na longa história da interpretação, encontramos as preocupações se movendo entre a intentio auctoris, intentio operis ${ }^{2} \mathrm{e}$ intentio lectoris.

Até o fim do século XIX, o enfoque principal era a intentio auctoris e suas indicações sociais e históricas. Ou seja, as conexões ao sujeito (sujeitos) da produção do texto eram a preocupação basilar da prática interpretativa. Para a hermenêutica isso significava, desde Schleiermacher (1998; 2006)3, compreender as intenções do autor materializadas na obra literária destinada aos ouvintes/leitores “originais”. Para a exegese bíblica isso significou, com todas as ferramentas necessárias e disponíveis, ser uma arqueologia do sentido por meio da qual se busca (buscava?) saber as intenções primeiras do texto sagrado. Isso significa uma dívida para com os autor (a) ou redatores(as) do texto com o qual se trabalha.

Há muito a exegese tem passado por renovações. Atualmente não podemos pensar, por exemplo, o método histórico-crítico sem levar em consideração as contribuições das ciências sociais, das ciências da linguagem, semiótica, etc. Durante muitas décadas, dizer exegese equivalia a dizer método histórico-crítico: critica textual, crítica literária, crítica e história das formas e dos gêneros literários, história das tradições, crítica e história da redação e da composição. Nos anos setenta e oitenta do século XX, vários novos métodos como também aproximações hermenêuticas surgidas de novos sujeitos e novas consciências começaram a abrir caminho na investigação científica dos textos bíblicos (KRÜGER, 2006, p.77).

\footnotetext{
${ }^{2}$ Intentio operis se deve, em certo nível, aos pressupostos estruturalistas, mas deixa um pouco de lado a preocupação com estruturas para observar as indicações do sentido nas marcas do próprio texto. Assim, o texto, que é aberto, tem seus próprios mecanismos de limitação dos usos: o texto, desde seu léxico, é limitador hermenêutico. Eco discute esses pontos, com exemplos e aplicações, em algumas de suas obras "pós-obra aberta". Cf. ECO, 2004; ECO, 2012. Ver também ECO, 2013.

${ }^{3}$ Ver especialmente SCHLEIERMACHER,1998, p.5-157. Cf. uma obra menor em português: SCHLEIERMACHER, 2006.
}

Horizonte, Belo Horizonte, v. 14, n. 43, p. 859-889, jul./set. 2016 - ISSN 2175-5841 
Os limites dos pressupostos do método histórico-crítico têm suas raízes no paradigma moderno-iluminista, que trabalha com categorias tais como intenção autoral e leitor real, com um pano de fundo de uma historiografia positivista que acredita na adequação do texto a acontecimentos históricos ${ }^{4}$. À vista disso, a exortação de Roger Chartier se torna fundamental para compreendermos os limites desses métodos, ou de qualquer outro, quando afirmam que o lugar de onde se faz o trabalho histórico impõe não somente os objetos próprios, mas também modalidades do trabalho intelectual, formas de escritura e técnica de provas e de persuasão (CHARTIER, 2009, p.18).

Filha de seu tempo, a exegese tradicional tem suas contribuições. Ela foi importante para o acúmulo de conhecimentos a respeito do horizonte histórico e cultural da Bíblia. Sua colaboração está exatamente nas pesquisas histórico-sociais, por meio das quais se reuniu um cabedal de informações sobre os contextos econômico, religioso, social, geográfico e político do mundo bíblico. Além disso, a exegese da Modernidade conseguiu romper com leituras literalistas e ingênuas. Contudo, como detectou J. Severino Croatto em seu clássico Hermenêutica Bíblica:

Ao lado destes indiscutíveis benefícios que convertem os métodos exegéticos em conquista inestimável, o seu uso exagerado, e às vezes reducionista, comporta alguns riscos [...]. Por outro lado, a preocupação em fundamentar a verdade das ciências do espírito, tão própria da consciência ocidental desde alguns séculos, concentrou a atenção sobre o sentido literal, entendido como o sentido "histórico". Isto é uma forma de reducionismo [...] desvirtua-se o processo por buscar o sentido na préredação. No caso de ênfase muito grande na intenção do autor ou do redator como sendo este o único sentido, corre-se o risco de enclausurar no passado a mensagem da Bíblia, entendida como "depósito" de um sentido fechado, coincidente com o pensamento de seu redator ou então dos pré-redatores do texto atual (CROATTO, 1986, p.14).

A descrição de Croatto mostra como a realidade e o passado são um problema insuperável para o método histórico-crítico. Uma das grandes crises para o exegeta é saber o que realmente o texto queria dizer quando foi escrito! Dos mais críticos aos

\footnotetext{
${ }^{4} \mathrm{O}$ pressuposto da analogia mostra que "a facticidade histórica de fenômenos é tanto maior quanto maior for a concordância entre estes outros fenômenos facilmente atestáveis e verificáveis". Cf. WEGNER, 1998, p. 18.
}

Horizonte, Belo Horizonte, v. 14, n. 43, p. 859-889, jul./set. 2016 - ISSN 2175-5841 
mais fundamentalistas, a intenção do autor, os desejos da comunidade original, etc. são como fantasmas que atormentam o sono do biblista. É como se ele estivesse sempre em dívida com o autor (a)/res ou redator (es/as) do texto com o qual trabalha. Por isso a maneira como a Semiótica da Cultura pensa o conceito de texto pode abrir alguns horizontes e gerar novas preocupações.

Na Semiótica da Cultura o conceito de texto acaba servindo de crítica a essa postura historicista e racionalista. Se cultura é fenômeno interativo, sem existência isolada e com um campo conceitual unificado fundado no processamento, na troca e na armazenagem de informações, uma organização de significantes e significados, ela por si já é um texto. Por isso, podemos concordar que a cultura como texto implica a existência de uma memória coletiva que não apenas armazena informações como também funciona como um programa gerador de novos textos, garantindo assim a continuidade (MACHADO, 2003, p.102). Assim, dentro da semiosfera um texto não é um fenômeno isolado, mas está em diálogo com outros textos.

Em consequência, no texto há outros sistemas de signos (inteiros ou parciais). Nesse sentido, a preocupação com a "intenção do passado", tão cara ao historicismo e quase uma patologia do método histórico-crítico, perde aos poucos o seu valor, abrindo as portas para a observação da criatividade do texto em organizar memórias e dar a elas sentido no seu discurso. E estas seriam parte constituinte da semiosfera que é refletida no texto.

Os pressupostos da semiótica da cultura mostram que a recepção do texto é uma grande oportunidade de aprofundamento da informação, pois há atualização de informações depositadas. São intenções latentes, às quais não seria possível chegar pela sua leitura original. Por isso, quanto mais o texto for lido, mais rico ficará, porque serão revelados aspectos do conteúdo que, em outros contextos de leituras, não poderiam ser acessados ou não desabrochariam. 
Consequentemente, a exegese deixa de ser uma arqueologia do sentido para se tornar observadora do texto como instrumento de diálogo com a cultura, pois sua releitura nas artes, gestos, etc. é também aprofundamento do seu significado. $\mathrm{O}$ histórico deixa de ser o passado, tornando-se o mundo que cerca os leitores e dá a eles a capacidade de acessar "mundos e fundos" inacessíveis, por exemplo, à audiência original.

\section{Realidade e texto}

O exegeta tem como objeto de pesquisa principal um documento. Este é a materializado em texto (CHARTIER \& CAVALLO, 1994) e segue uma dinâmica própria da linguagem. Por isso, as pesquisas e os pressupostos fundamentados pelas teorias literárias precisam ser levados em consideração, especialmente para pensarmos as bases metodológicas de nosso trabalho a fim de, assim, avançarmos para a análise narrativa.

Frye, seguindo as pesquisas de Vico, traça uma história da linguagem para localizar os textos. Como ele mesmo diz, linguagem é a "sequência modal de estruturas postas em palavras mais ou menos traduzíveis” (FRYE, 2004, p. 27). Esses modos, que não são excludentes, atravessariam a variedade das langues/línguas em uso e seriam afeiçoados e condicionados, embora não determinados, por elas. Nessa perspectiva, há três momentos ou fases no ciclo histórico da linguagem: as fases hieroglífica, hierática e demótica. $\mathrm{Na}$ fase hieroglífica, também conhecida como metafórica ou poética, há pouca separação entre sujeito e objeto, pois estão ligados por um tipo de energia comum a ambos. Nesse momento da história da linguagem, acreditava-se na potencialidade da palavra, como se a sua correta articulação pudesse dar corpo a esse potencial comum (FRYE, 2004, p.28), como se ela carregasse um poder mágico de manipulação e intervenção na realidade. Na fase hierática, também chamada de metonímica, estamos no período da linguagem que remonta a Platão e que está bem presente na escolástica medieval, na qual as palavras são exteriorizações de 
pensamentos e estão no lugar das coisas. Diferente da fase metafórica da linguagem, esta valoriza a lógica e estruturação coerente das palavras, razão por que há supervalorização dos silogismos.

A última fase, demótica, também conhecida como descritiva, está ligada à linguagem científica, fruto da observação e expressão do fato que descreve. Ela pode ser situada no séc. XVI e chega ao seu ápice no séc. XVIII. Diferentemente das anteriores, nessa fase há uma clara separação entre sujeito e objeto. Como explica o crítico literário:

Aqui partimos de uma separação muito clara entre sujeito e objeto, onde o sujeito se expõe, através da experiência dos sentidos, ao impacto de um mundo objetivo. $\mathrm{O}$ mundo objetivo é a ordem da natureza; o pensamento ou a reflexão seguem as sugestões da experiência dos sentidos a as palavras são o servomecanismo da reflexão. Prossegue o uso da prosa contínua, mas todos os procedimentos dedutivos se vêem (sic) cada vez mais subordinados a um processo prévio indutivo e de coleta de material - de fatos, ao impacto de um mundo objetivo. O mundo objetivo é a ordem da natureza (FRYE, 2004, p.36).

As nítidas testemunhas textuais de caráter metafórico na Bíblia e a própria primordialidade da linguagem poética em relação à prosa levam o crítico literário canadense a indicar que, como a linguagem em si é, em algum nível, sempre metafórica, até mesmo as expressões mais descritivas e científicas da realidade, ou qualquer objeto, sempre serão construção. Ele diz:

A única coisa que as palavras podem fazer com uma precisão e acuracidade reais é permanecerem juntas. A partir de certo ponto a linguagem começa a perder acuracidade na descrição: o relato mais fielmente descritivo de qualquer coisa terminará por abandonar o que descreve em direção a suas ficções gramaticais autocontidas como sujeito, predicado e objeto. Os eventos descritos na Bíblia são, no dizer de alguns eruditos, "eventos de linguagem", trazidos até nós apenas por palavras; e são as próprias palavras que guardam o sentido de autoridade, não os eventos que descrevem (FRYE, 2004, p.86).

Desse modo, temos aqui uma crítica indireta aos pressupostos do método histórico-crítico (o que poderia ser aplicado a qualquer ciência, seja ela mais "dura que ferro"!), que acredita chegar, por exemplo, às realidades histórico-sociais do 
texto por meio de leituras críticas - ou até mesmo expressar esse mundo como um reflexo da descrição do exegeta.

O exegeta tradicional até admite o caráter poético de alguns textos, mas logo pergunta pelo seu lugar vivencial, Sitz im Leben, ou onde foi usado ou originado. Por outro lado, há a leitura fundamentalista, que afirma o texto como se ele fosse o reflexo claro do mundo descrito. Tanto em um como no outro há uma ênfase na realidade além-texto. Se o método histórico-crítico tenta fazer do texto um instrumento de descrição de alguma realidade, o fundamentalista já encontra no próprio texto a sua descrição. Tanto um quanto o outro acabam tratando “demoticamente" um texto cheio de indícios poético-metafóricos, como é natural aos textos hieroglíficos.

Há tempos a teoria literária, com bases aristotélicas e trabalhando com conceitos tais como mimesis e poiesis, descreve a relação da literatura com a realidade de maneira inovadora e abre novos caminhos para o trato com o texto, tornando-o menos espelho do mundo do que reconstrutor criativo a partir do olhar do artista.

Soma-se a esses elementos o "estético", entendido como a função do texto primordialmente voltada para si mesma, mediante seus dados internos, que o mantém em pé e lhe dá densidade, independente de vínculos práticos ou funcionais com o real. Tais conceitos teóricos não desconectam a obra literária da realidade, mas permitem entender que dela se ausenta para construir outra realidade, esteticamente bela e convincente (FERREIRA, 2008, p.10).

Soma-se a essas lucubrações o crítico literário Tzvetan Todorov. Ao falar da leitura de textos literários, ele defende ser preciso revisar o conceito de realidade. Por conseguinte, fala-se de verossimilhança (TODOROV, 1970, p. 90-96), da retórica clássica, que também é melhor aplicável aos textos hieroglíficos, tais como a Bíblia. 
Segundo Todorov, a verossimilhança deve ser julgada por dois outros tipos de discurso: regra do gênero e opinião comum (TODOROV, 1970, p.92-93). A respeito da regra do gênero, ele defende que a obra é verossímil de acordo com sua participação e conformidade à expectativa de um gênero: "o verossímil, tomado neste sentido, designa a relação da obra com o discurso literário, mais exatamente, com certos elementos dêle (sic) que formam um gênero" (TODOROV, 1970, p.92). Talvez isso pareça um tanto quanto reducionista, mas na mesma argumentação o crítico literário explica que pertencer a um gênero é, de direito, universal, porque uma obra pode se perceber como uma instância particular com relação a um gênero geral, mesmo que este contenha apenas tal obra. Frye concorda com isso, pois admite que a literatura sempre está, ainda que no nível da linguagem, no claustro dos gêneros. Mesmo havendo a criatividade do autor, ele sempre falará a partir de padrões de linguagem, seja se afastando de um ou se aproximando de outro gênero literário (FRYE, 1957, p.11-13).

A outra descrição para análise de verossimilhança está ligada à expectativa de realidade que ele chama de opinião comum:

\begin{abstract}
Mas existe outra verossimilhança: a que se considerou amiúde como uma relação com o real. Aristóteles, todavia, já havia dito claramente que não se tratava de uma revelação entre o discurso e seu referente (relação de verdade), mas entre o discurso e o que os leitores acreditam verdadeiro. A relação se estabelece, então, no caso, entre a obra e um discurso difuso, que pertence em parte a cada um dos indivíduos de uma sociedade, mas cuja propriedade nenhum dêles (sic) pode reclamar; por outras palavras à opinião comum. Esta não é evidentemente a "realidade", mas somente um discurso terceiro, independente da obra. A opinião comum funciona, pois, como uma espécie de regra de gênero, que se relaciona com todos os gêneros (TODOROV, 1970, p.93).
\end{abstract}

Nesta perspectiva, o verossímil equivale às convenções contemporâneas, que determinam as regras da realidade e não a realidade em si. $\mathrm{O}$ verossímil seria o mundo das convenções aceitas e a coadunação da narrativa às regras contemporâneas. Dessa maneira, o texto deixa de ser um objeto para se averiguar se é fonte de "realidades" ou "mentiras" históricas para ser avaliado em suas 
aproximações ou distanciamentos das convenções, que são invenções, por sua vez, do crítico literário.

$\mathrm{Na}$ história da leitura dos textos bíblicos, como na dos textos em geral, a preocupação pelos sentidos talvez tenha sido o grande ponto de convergências e divergências. A exegese histórico-crítica, por sua vez, fez (e continua fazendo) da arqueologia do passado o seu grande objeto de pesquisa, mesmo que renovada por outras ciências.

Seguir o clássico caminho da tradicional exegese é buscar o mundo fora do texto, o qual se torna o mapa indicador do percurso para se descobrir a intenção do autor, o qual tinha seus ouvintes como aqueles que deveriam entender bem o que ele desejava, de modo que a pragmática do enunciado se realizasse ou fosse desqualificada por seus receptores.

Pelo que parece, uma das forças para destronização do método históricocrítico foi seu estatuto epistemológico, a saber, a interdisciplinaridade. O mesmo método que permite o diálogo com outros referenciais acaba recebendo destes mesmos as críticas relacionadas aos seus pressupostos e funcionamento. Além disso, as novas perspectivas metodológicas, mesmo que a exegese tradicional tenha se permitido dialogar, geraram profundas e renovadoras mudanças nas perguntas feitas aos textos, deixando de girar em torno da "autoria", "fundo histórico" e "genealogia de tradições".

O avanço metodológico, que exorcizou a univocidade em favor do paradigma historicista, só foi possível com os referenciais teóricos das diversas ciências humanas, os quais possibilitaram revisão e críticas aos pressupostos do método tradicional.

Podemos, então, listar alguns problemas do método histórico-crítico:

I. A crença em um sentido original, histórico que pode ser resgatado, "que sai do texto" (exegese) precisa ser reavaliada. A própria questão do histórico deve ser 
alargada do olhar "para trás" para o olhar "para frente" do texto, porque histórico também é o lugar da recepção, que não é simplesmente uma danificação ou distorção do sentido do texto. Pelo contrário, como potencialmente aberto a novos sentidos, o texto ganha na recepção novas funções e responde a outros desafios. Mesmo correndo o risco de idealizar certas formas de recepção, a história de sua leitura revelará aprofundamento de sentidos, os quais não seriam possíveis no primeiro acesso. Desta forma, passa-se do original para o originário ou paradigmático.

II. O problema do paradigma do sujeito, que acredita na objetividade, em neutralidades e positivismos metodológico 5 que, na verdade, escondem exatamente o eurocentrismo próprio da razão instrumental.

III. A percepção de que a história da formação do texto é sinônimo de significado. $\mathrm{Na}$ verdade, há nesse procedimento a confusão entre signo e significado, uma vez que o sentido não está no processo da formação das tradições, mas na relação dos signos do texto que, por sua vez, está em diálogo com diversos outros signos que lhe dão possibilidade de ser texto.

IV. A questão acima pode abrir outra: o pressuposto mecanicista e sempre vinculado às materialidades, tais como a crítica da tradição, como se os temas e imagens estivessem sempre atrelados a influências materiais e refletissem os livros que o autor leu (SIMIAN-YOFRE, 2011, p. 104). Isso perde de vista que o sistema próprio da língua é dialógico: um discurso é perpassado por outros discursos (dialogismo) como também a própria cultura é conjunto de textos em diálogo ${ }^{6}$.

V. O problema da relação com a realidade é outra questão dos pressupostos do método tradicional, pois ele não leva em consideração o nível narrativo e sempre ficcional da descrição da realidade e não percebe, por exemplo, que o "autor" mente gramaticalmente.

\footnotetext{
${ }^{5}$ Para discussão e novos rumos sobre a inter-relação e a relação do sujeito-objeto, podemos citar alguns trabalhos que desarticulam a racionalidade moderna, logocêntrica. Cf. ECO, 2012; HABERMAS, 2002; HALL, 2002; ISER, 1996/1999; JAUSS, 1992.

${ }^{6}$ Para saber mais sobre essa perspectiva a respeito dos textos, cf. BAKHTIN, 2010; CLARK, 1984; BARROS \&FIORIN, 2003.
} 
VI. A separação do sujeito e objeto, como se este estivesse imunizado pelo método, deixa de lado a imprescindível relação entre pesquisador e objeto. No encontro se constrói o resultado da pesquisa, pois o olhar, as perguntas, os métodos e metodologia aplicados ao trabalho são influenciados pelos interesses, empaticamente estabelecidos, pelo pesquisador. Consequentemente, não se descobre o objeto, mas cria-o.

Por isso, deve-se colocar na discussão a Narratologia que é, nas ciências bíblicas, resultado dos diálogos entre as rígidas ferramentas da exegese tradicional e as provocações, para usar um termo de H. R. Jauss, da teoria literária (JAUSS, 1994). A Narratologia trabalha com instâncias narrativas por meio das quais se avança para novos conceitos, menos positivistas, e se chega a ideias tais como autor-implícito, narrador, leitor-implícito, narratário e outras. Estes conceitos deixam de lado preocupações historicistas rankeanas, que se detinham em apresentar aos leitores os "fatos", como se a história fosse objetiva (BURKE, 1992, p. 7-38).

A Narratologia pode responder ao que Eco diz como necessário no trabalho com o texto: "isso quer dizer que o texto interpretado impõe restrições a seus intérpretes. Os limites da interpretação coincidem com os direitos do texto (o que não quer dizer que coincidem com os direitos de seu autor)” (ECO, 2004, p. XXII).

\section{Leitura de textos sagrados e as teorias narrativas.}

Todorov distingue duas posturas nos estudos literários. A primeira observa na obra literária o fim último; a segunda, a manifestação de "outra coisa" - as quais não são, segundo ele, incompatíveis (TODOROV, 1970, p.11).

A partir de seu resumo didático, percebemos que a análise narrativa estaria entre as disciplinas que se aproximam da obra literária da segunda perspectiva, pois nela a literatura não é considerada como manifestação de uma estrutura 
inconsciente ou de uma concepção filosófica, mas como um discurso que se faz conhecer por si mesmo. Naturalmente, a obra literária é vista, nesse caso, antes como uma construção verbal do que como a representação de uma realidade; busca-se a explicação de suas particularidades nas relações que entretêm seus elementos constitutivos, ou nas relações que ela própria tem com outras obras; não se busca as causas e sim as razões que justificam a existência de um fenômeno literário (TODOROV, 1970, p.12).

A Narrativa é a representação de dois ou mais eventos reais ou fictícios em uma sequência, sem que um implique ou pressuponha o outro. A narrativa, entre outras coisas, é a coleção de signos que podem ser agrupados em várias categorias. Mais particularmente, nas narrativas escritas certos recursos e combinações dos signos linguísticos que a compõem constituem signos de narração: eles representam a atividade narrativa, sua origem e sua destinação. Outros recursos e combinações constituem signos do narrador: eles representam os eventos e situações recontados (PRINCE, 1982, p.7).

A disciplina por excelência que estuda a narrativa é a Narratologia. Os métodos da Teoria Narrativa são inspirados pelos linguistas modernos que demonstraram, por meio da análise sincrônica da linguagem, como a narrativa desenvolve manifestações de oposições e combinações de elementos básicos (fonemas, morfemas, sintagmas, etc.). De maneira similar, a Narratologia tenta traçar como sentenças se tornam narrativa, ou como a narrativa emerge de textos narrativos e palavras em página (FLUDERNIK, 2009, p.8).

Em suma, Teoria Narrativa ou Narratologia é o estudo da narrativa como gênero. Seu trabalho é descrever as constâncias, variabilidades e combinações típicas das narrativas e esclarecer como aquelas características dos textos narrativos estão conectadas ao quadro dos modelos teóricos (FLUDERNIK, 2009, p.9). Ainda sobre o trabalho da Narratologia, como uma leitura pragmática, ela está preocupada com "como" o autor comunica a sua mensagem. Interessa-se pelas 
estratégias por meio das quais o texto organiza a expectativa de decifração do sentido pelo leitor. Assim, a Narratologia é descritiva, pois observa as combinações dos signos de linguagem na narrativa; é também interpretativa, porque percebe as estratégias do texto para gerar sentido e movimentar seus leitores. D. Marguerat e Y. Bourquin conseguem definir bem as diferenças dos pressupostos das leituras histórico-crítica, estrutural e narrativa:

O que busca a análise histórico-crítica? Ela se interessa pelo acontecimento histórico que o texto relata e pelas condições em que o texto foi escrito. De modo geral, seu interesse se fixa no mundo (histórico) por trás do texto [...]. Que busca a análise estrutural ou semiótica? Este tipo de leitura gravita em torno do polo sul do eixo da representação, enquanto a análise histórico-crítica se localiza no norte. Não é, absolutamente, o mundo representado que lhe interessa, mas o funcionamento da linguagem, segundo um princípio que chamamos de postulado de imanência: nada fora do texto, nada além do texto, e o texto todo (tudo, no texto, é levado em conta; nenhuma informação é tirada de fora do texto). Sua pergunta: como é que faz o texto para produzir sentido? [...]. Onde situa a análise narrativa? Não no eixo da representação, mas no da comunicação. Sua pergunta: como é que o autor comunica sua mensagem ao leitor? Por meio de qual estratégia o autor organiza a decifração do sentido pelo leitor? O estudo, aqui, recai sobre as estruturas que permitem à mensagem atingir o efeito buscado pelo emissor. As coisas poderiam ser ditas diferentes. O eixo da comunicação alinha os três polos sem os quais não é possível comunicação: autor (destinador), a mensagem, o leitor (destinatário) [...]. A Análise narrativa se orienta, prioritariamente, não pelo autor, nem pela mensagem, mas pelo leitor, considera o efeito da narrativa no leitor, leitora, e a maneira como o texto o faz cooperar no deciframento do sentido (MARGUERAT \& BOURQUIN, 2009, p. 15-17).

A Teoria Narrativa se utiliza de conceitos, formando uma espécie de gramática narratológica, por intermédio da qual se lêem as narrativas. Um deles é o conceito de narrador. Este é considerado como agente integrado ao texto, responsável pela narração. Ele não é o autor empírico ou os personagens. Ele é a voz que conduz o leitor e guia a história.

No mundo de fala inglesa os termos overt e cover são frequentemente utilizados para se referirem a algo identificável em oposição a um narrador não identificável (FLUDERNIK, 2009, p.21). Um narrador perceptível (overtnarrator) 
é aquele que pode ser visto claramente ao se contar uma história - embora necessariamente um narrador sempre é de primeira pessoa - e, ao articular seus propósitos e pontos de vista, faz sua presença ser percebida estilisticamente, assim como no nível da metanarrativa. Tal narrador participa ativamente na história.

O narrador tem um ponto de vista, que é o apresentado pela narrativa. Por meio deste o mundo da narrativa é construído. Como diz Todorov: "o fato é que as visões são de primordialíssima importância. Em literatura, jamais temos de havernos com acontecimentos ou fatos brutos, e sim com acontecimentos apresentados de determinada maneira" (TODOROV, 1970, p.41).

Essa narração tem a linguagem como o meio pelo qual os textos narrativos se constituem e também é responsável pelo mundo ficcional criado pelas narrativas. Isso nos mostra que a linguagem é meio e objeto de representação. A Narratologia é, então, o estudo da forma e função da narrativa (PRINCE, 1982,p.4). Essa é a ferramenta para percebermos como o narrador do Apocalipse de João gera sobre o leitor, com as imagens de caos, a sensação de desordem e violência.

Para a Narratologia, o autor não é o autor real, aquela entidade histórica que produz um texto e vive fora dele, mas o autor implícito. Este é o que a obra revela por suas escolhas narrativas:

Um autor, com efeito, se objetiva em sua obra, não pela vida que leva fora dela, mas pela orientação que dá a seu texto. Pôr-se em busca do autor implícito é observar que estratégia narrativa ele emprega, que estilo escolhe, como faz intervir seus personagens, que sistema de valores conduz a narrativa. A imagem do autor implícito resulta na soma das escolhas de escrita identificadas no texto. Assim, a cada obra literária corresponde um autor implícito, quer dizer, a imagem do autor tal qual se desvela nessa obra (MARGUERAT \& BOURQUIN, 2009, p.25).

Podemos diferenciar o narrador do autor implícito dizendo que aquele é a voz que guia o leitor na narrativa, enquanto este é o princípio que criou o narrador, assim como todos os outros elementos da narrativa. A ideia de um autor implícito nos abre a possibilidade de lermos o texto com menos inocência, pois não 
precisamos marcar referências históricas à imagem criada pelo texto, pois não nos importa quem realmente está por trás das linhas, pois esse "ser" quase assombroso pode muito bem fingir, mentir sobre si mesmo e manipular suas opiniões, dandonos, pela metade, a imagem do seu rosto. Por isso, o que nos importa são as estratégias do texto.

Como estamos lidando com um texto que propõe uma interpretação “outra”, em linguagem simbólica, a respeito da sociedade e ordem visíveis aos seus concidadãos, o conceito de autor implícito se torna mais frutífero, pois a ficção narrativa autoriza desenvolver um mundo imaginário que não coincide com a realidade imediata que o cerca.

A Narratologia se insere nas metodologias consideradas pragmáticas, que questionam os efeitos sobre o leitor, observando os indícios pragmáticos, que são as instruções sobre como o texto quer que se estabeleça sobre o leitor (POWELL, 1990). Esse referencial metodológico ajudará na identificação das estratégias textuais para organização das memórias e como fez dialogarem os conteúdos do cânon e do arquivo na memória cultural. Observando na narrativa suas expressões de tempo, personagem, enredo, enquadramentos, o narrador, o autor, etc., podese observar, em nível narrativo, como as memórias na relação diacrônica (as que se perenizaram) e sincrônicas (as contemporâneas) se interpassaram para a produção de sentido e interpretação de mundo na semiosfera em que determinada narrativa se insere.

Para observação da organização de tradições, da formação de discursos e do surgimento e compreensão de enunciados7, reconhece-se a insuficiência da exegese tradicional. Esta crítica baseia-se, entre outras coisas já apontadas, em sua quase não solucionável dependência à busca de apropriações diretas, dependência à materialidades textuais, seu positivismo historicista e criticismo infértil. Portanto, as perspectivas da Crítica da Tradição, por exemplo, como descreve Simian-Yofre,

\footnotetext{
${ }^{7}$ Para a relação e definição de enunciado e discurso empregamos aqui as pesquisas de M. Bakhtin, que diz ser o discurso os valores e conhecimentos culturais, enquanto o enunciado é a materialização linguística, cf. BAKHTIN, 2003.
}

Horizonte, Belo Horizonte, v. 14, n. 43, p. 859-889, jul./set. 2016 - ISSN 2175-5841 
que seria uma espécie de observação das obras literárias do repertório do autor dos textos (SIMIAN-YOFRE, 2011, p.104), não são frutíferas.

Nesta proposta de renovação ou diálogo metodológico, a preocupação da exegese não se prenderá às "influências literárias" simplesmente, mas, por exemplo, observarão intertextualidades e interdiscursividades. Por isso, quando nos referimos a memórias, estamos lidando com expressões de contextos prévios que se movimentam e permeiam coletivamente os imaginários recebidos criativamente. Neste sentido, memórias servem para interpretação de mundo e são reatualizadas em uma organização narrativa, que por si só é poética, metafórica e ficcional.

\section{Conclusão}

Para leitura dos textos e narrativas sagrados, especialmente nas ciências bíblicas, os métodos historicistas foram, por vezes, privilegiados. Contudo, há anos estes são alvo de fortes releituras e críticas. Neste trabalho, foram apresentados conceitos e pressupostos epistemológicos para construção de um referencial teórico que possibilitasse novas aproximações, preocupações e leituras. Para isso, expus os conceitos de texto, cultura e memória a partir das pesquisas da Semiótica da Cultura e as intuições da Narratologia. A proposta não é de substituição rápida de um pelo outro (pelos outros), mas de diálogo e aproximações. Todo referencial teórico tem seus limites e o próprio objeto modelará a maneira para sua aplicação. Além disso, mesmo com seus limites, o método hitórico-crítico deixou grandes contribuições, as quais podem ser utilizadas, mesmo subvertendo seus pressupostos, na aplicação da semiótica da cultura, narratologia ou qualquer metodologia disponível.

Por fim, pode-se concluir que as pesquisas às obras produzidas pelas religiões, e suas linguagens, precisam repensar seu conceito de história, intenção autoral e acesso à realidade do passado. Por isso, a semiótica da cultura e os demais 
métodos das ciências da linguagem são tão importantes, porque ajudam na superação de positivismos inférteis, na aceitação da criatividade do leitor, da intransponível deformação da tradução e a morte do autor, que é mais uma entidade a ser exorcizada do que objetivo da pesquisa.

Assim, possibilita-se a oportunidade de pensarmos a leitura de textos sagrados de maneira mais "flexível" e abre as portas para novas experiências hermenêuticas, as quais poderão dialogar, sem preconceitos historicistas, com as novas teorias da linguagem.

\section{REFERÊNCIAS}

ALTER, Robert. A arte da narrativa bíblica. São Paulo: Cia das Letras, 2007.

ALTER, Robert; KERMODE, Frank (org.). Guia literário da Bíblia. São Paulo: Unesp, 1997.

AMIHAI, Miri; COATS, George W; SOLOMON, Anne M. (Ed.). Narrative Research the Hebrew Bible. Semeia, Missoula, n.46, p. 1-178, 1989.

BAKHTIN, M. Estética da criação verbal. São Paulo: Martins Fontes, 2003.

BAKHTIN, M.; VOLOCHINOV, Valentin. Marxismo e filosofia da linguagem. São Paulo: Editora Hucitec, 2010.

BARROS, D. L.; FIORIN, José Luiz (org.). Dialogismo, polifonia, intertextualidade. 2. ed. São Paulo: Editora da Universidade de São Paulo, 2003.

BLOCH, Marc. Memória coletiva, tradição e costume: a propósito de um livro recente. In: BLOCH, Marc. História e historiadores: textos reunidos por Étienne Bloch. Lisboa: Editorial Teorema, p. 78-83, 1998.

BURKE, Peter. Abertura: a nova história, seu passado e seu futuro. In: BURKE, Peter. A escrita da história: novas perspectivas. São Paulo: Editora UNESP, p. 7-38, 1992.

CHARTIER, R. A história ou a leitura do tempo. Belo Horizonte: Autêntica, 2009.

CHARTIER, Roger; CAVALLO, Guglielmo. História da leitura do mundo ocidental. São Paulo: Ática, 1994.

CLARK, K.; HOLQUIST, M. Mikhail Bakhtin. Cambridge: Harvard University Press, 1984 . 
CROATTO, J. S. Hermenêutica bíblica. São Leopoldo: Sinodal; São Paulo: Paulinas, 1986.

ECO, Umberto. Interpretação e superinterpretação. São Paulo: WMF Martins Fontes, 2012.

ECO, Umberto. Obra aberta: forma e interdeterminação nas poéticas contemporâneas. 9. ed. São Paulo: Perspectiva, 2013.

ECO, Umberto. Os limites da interpretação. 2. ed. São Paulo: Perspectiva, 2004.

ERLL, Astrid. Memory and Culture. New York: Palgrave Macmillan, 2011.

ERLL, Astrid; NÜNNING, Ansgar (ed.). Cultural Memory Studies: An International and Interdisciplinary Handbook. Berlin; New York: Walter de Gruyter, 2008.

FERRARI, Mônica Rebecca. A memória da cultura e a memória na mídia em produtos autovisuais infanto-juvenis. In: MACHADO, I. Semiótica da cultura e semiosfera. São Paulo: FAPESP; Annablume, 2007.

FERREIRA, J. C. Leonel. A Bíblia como literatura: lendo as narrativas bíblicas. Revista Eletrônica Correlation, São Bernardo do Campo, v.7, n.13, 2008, p.10. Disponível em: <https://www.metodista.br/revistas/revistas-

ims/index.php/COR/article/view/1650/1646>. Acesso em: 19 nov. 2015.

FLUDERNIK, Monika. An Introduction to Narratology. New York: Abingdon Press, 2009.

FRYE, Northrop. Anatomia da crítica. São Paulo: Cultrix, 1957.

FRYE, Northrop. Código dos códigos: a Bíblia e literatura. São Paulo: Boitempo, 2004.

GUNN, D. M. New Directions in the Study of Biblical Hebrew Narrative. Journal of the Study of the Old Testament, New York, n. 39, p. 65-75, 1979.

HABERMAS, J. Pensamento pós-metafísico: estudos filosóficos. Rio de Janeiro: Tempo Brasileiro, 2002.

HALBWACHS, Maurice. A memória coletiva. São Paulo: Centauro: 2006.

HALL, Stuart. Identidade cultural na pós-modernidade. Rio de Janeiro: DP\&A Editora, 2002.

ISER, Wolfgang. Ato da leitura. São Paulo: Editora 34, 1996/1999.

JAUSS, H. R. Experiência estética y hermética literária. Madrid: Taurus, 1992.

JAUSS, H. R. História da literatura como provocações à teoria literária. São Paulo: Ática, 1994. 
KRÜGER, René. Uma aproximação estrutural a Lucas 1-4. Ribla, Petrópolis, n. 53, p. 77, 2006/1.

LÓTMAN, I. As três funções do texto. In: LÓTMAN, I. Por uma teoria semiótica da cultura. Belo Horizonte: FALE; UFMG, 2007.

LÓTMAN, I. La semiosfera I: semiótica de la cultura e del texto. Madrid: Ediciones Cátedra, 1996.

LÓTMAN, I. La semiótica de la cultura y el concepto de texto. Escritos, Puebla, n.19, p. $19,1993$.

LÓTMAN, I. La semiótica de la cultura y el concepto de texto. In: LÓTMAN, I. La semiosfera I: Semiótica de la cultura e del texto. Madrid: Ediciones Cátedra, 1996. p. 7782.

LÓTMAN, I. On the Semiosphere. Sign Systems Studies, Tartu, v.33, n. 1, p. 213, 2005.

LÓTMAN, I. Tese para uma análise da semiótica da cultura (Uma aplicação aos textos eslavos). In: MACHADO, Escola de semiótica: a experiência de Tártu-Moscou para o estudo da cultura. São Paulo: Ateliê Editorial; FAPESP, 2003.

LÓTMAN, I. Universe of the Mind: A Semiotic Theory of Culture. Bloomington; Indianapolis: Indiana University Press, 1990.

LÓTMAN, I.; USPENSKII, Bóris. Sobre o mecanismo semiótico da cultura. In: MACHADO, I. (org.). Ensaios de semiótica soviética. Lisboa: Novo Horizonte, p. 37-66, 1981.

MACHADO, I. Escola de semiótica: a experiência de Tártu-Moscou para o estudo da cultura. São Paulo: Ateliê Editorial; FAPESP, 2003.

MARGUERAT, D.; BOURQUIN, Y. Para ler as narrativas bíblicas: iniciação à analise narrativa. São Paulo: Loyola, 2009.

NOGUEIRA, Paulo A. S. Hermenêutica da recepção: textos bíblicos nas fronteiras da cultura e no longo tempo. Estudos de Religião, v.26, n.42, 2012a, p.22. Disponível em: <https://www.metodista.br/revistas/revistasims/index.php/ER/article/view/3095/3086>._Acesso em: 23 nov. 2015.

NOGUEIRA, Paulo A. S. Religião como texto: contribuições da semiótica da cultura. In: NOGUEIRA, Paulo A. S. (Org.). Linguagens da religião: desafios, métodos e conceitos centrais. São Paulo: Paulinas, p. 13-30, 2012 b.

POWELL, M. A. What is Narrative Criticism?. Minneapolis: Fortress Press, 1990.

PRINCE, Gerald. Narratology: The Form and Functioning of Narrative. Berlin; Amsterdam; New York: Mouton Publishers, 1982. 
RAMOS, Vaz A. et al. Semiosfera: explosão conceitual nos estudos semióticos da cultura. In: MACHADO. Semiótica da cultura e semiosfera, Semiótica da cultura e semiosfera. São Paulo: FAPESP; Annablume, 2007.

RICOEUR, Paul. A memória, a história, o esquecimento. Campinas: Editora da Unicamp, 2007.

SANTOS, Myrian S. dos. Memória coletiva e teoria social. São Paulo: Annablume, 2003 .

SCHLEIERMACHER, Friedrich D. E. Hermenêutica: arte e técnica da interpretação. Petrópolis: Vozes, 2006.

SCHLEIERMACHER, Friedrich D. E. Hermeneutics and Criticism and Other Writings. Translated and Edited by Andrew Bowie. Cambridge: Cambridge University Press, 1998.

SIMIAN-YOFRE, H. (org.). Metodologia do Antigo Testamento. São Paulo: Loyola, 2011.

TODOROV, T. Estruturalismo e poética. São Paulo: Cultrix, p. 90-96, 1970.

VIEIRA, Jorge de Albuquerque. Semiosfera e o conceito de Umwelt. In: MACHADO, Irene (Org.). Semiótica da cultura e semiosfera. São Paulo: FAPESP; Annablume, p. 99-113, 2007.

WEGNER, Uwe. Exegese do Novo Testamento: manual de metodologia. São Leopoldo: Sinodal; São Paulo: Paulus, 1998. 